\title{
The Research on Relative Rationality in Judicial Reform
}

\author{
Yao Feng ${ }^{1, \text { a }}$ \\ ${ }^{1}$ Sichuan University Law School, Block 2 Chuan Road, Shuangliu County, Chengdu City, Sichuan \\ Province, 610207 \\ hunter2011@foxmail.com
}

Keywords: Reason, Judicial rationality, justice reform

\begin{abstract}
The reason and rationality are very important categories during the process of developing and implementing law. It is exactly under the leadership of the reasonable doctrine that mankind begins to pay attention to and high praise the written law, making the law determinate, stable and predictable. However, the inherent lagging of the written law contributes to a kind of unavoidable tension between written law and social development. The abstract legal rules cannot form a corresponding relation that direct firm word does not change with complicated social life. Thus, regular universality is at a loss as to what to do in front of the variety of social life sometimes. In the judicial course, when disputes occur, there is a judicial responsibility according to the social major values, regarded as "an end line of just of the society," objective law and operating the law to award these disputes rationally by itself of the social development. So judicial rationality research is a avoided subject in the course of rule by law.
\end{abstract}

\section{Introduction}

Because of the enactment innate lag, the pursuit of justice is a relatively reasonable and inevitable complement to a country under the rule of law. Construction of rule of law cannot be divorced from historical track. Of course, the rule of law in our country has its own unique realistic background and conditions. During Chinese modernization, historical experience has repeatedly suggested that when the society is in transition, countries with unsettled legislation are often unable to respond duly to various interests, in particular, changes in the society. If the judiciary can perform well in protection of various interests and reasonable redistribution of functions, it is possible to provide timely legal remedies against damages caused by misconducts which can happen at any time. Consequently, social contradictions can be effectively alleviated, thus leading to a smooth social transformation. If the allocation process is completed in the interests of rancor and without resorting to judicial relief from the sense of reasonability, it is easy to bring despair and push the society into an abyss. It can be said that justice relative rationality in favor of civil rights and protection of relief helps resolve social conflicts, maintain social order, and at the same time, promote steady and continuous development of the society. With the development of contemporary Chinese judicial reform, it is of utmost urgency to call for the guiding role of justice relative rationality. [1]

\section{The Concept of Judicial Relative Rationality}

Aimed at meeting people's needs, judicial relative rationality means that law is consistent with the objective laws of social development and the law of its own development properties. Chinese scholar Professor Zhou Shizhong has conducted systematic research on the development trajectory of judicial relative rationality. Along with basic research of Chinese and foreign scholars on judicial relative rationality, he summed up judicial relative rationality in a dialectical and materialist way. He believes that factors associated with the definition of judicial relative rationality include four: the value required, objective necessity, natural law (the extent of feasibility), and subjective will. By a combination of these four factors, the formation of a relatively reasonable judicial judgment consists of two criteria, namely the needs of the law and the law of regularity. Desirably, being in line with the people means to create a body of history needs; being in line with the law refers to the law of 
development of productive forces and social relations and the law operated by their own decision. Therefore, the value of the unity of justice and truth is the law of relative rationality. Justice relative rationality is the law to meet the people's needs and property law in line with the objective laws of social development law and the laws of its own development [2].

\section{The Characteristics of Judicial Relative Rationality}

Objectivity. The objectivity of judicial relative rationality means that the needs and regularity of judicial cooperation is objective. This objective attribute of justice reflected a certain value judgment in the human mind that only justice is relatively reasonable, and from the objectivity of justice property, justice relative rationality has become a forest without trees. From the perspective of objectivity to relative rationality, the first law of nature should be analyzed. The ultimate essence of law is attributed to physical constraints, and is one of outstanding contributions of the Marxist jurisprudence theories.

Subjectivity. Justice is inseparable from the relative rationality of a person's subjective will. About justice rational and irrational judgment or causality, it is a logical relationship. The standard is based on the person's own judgment of the need to prevail. Clearly, relative rationality is inseparable from the consciousness of judicial body. However, it should also be noted what the needed body is, what the common needed body is, and what kind of law is required in order to meet these common needs. Behind these phenomena hides a more profound factor, which determines the physical aspects of people's needs and determines that the judiciary can meet these needs. Therefore, objectivity cannot be denied when in the affirmative of the subjectivity of judicial relative rationality.

History. Justice relative rationality, like everything else, has its own inherited history. However, over time, the concept of judicial function and instrumental rationality lacked sense, and also lost relative rationality of value. So, justice is relatively reasonable. From a longitudinal point of view, it is a historical precipitate. From a historical cross-section view, it is always being affected by economic restructuring, cultural development, and political systems under a specific historical conditions, and other factors caused by objective constraints.

Times. Productive forces are different in different times. In the face of the evolving, productivity determines the inevitable changes of relations of production and the emergence of new requirements. Therefore, with the progress of the era and as factors for making relatively reasonable judicial judgment changes, justice is bound to continue as a superstructure which adapts itself in a timely manner, so as to eventually fulfill the requirements of the times. From this perspective, justice relative rationality has the characteristics of the times.

\section{Features and Deficiencies of the Existing Judicial System}

China's current judicial system has the following salient features.

Firstly, People's Courts and People's Procuratorate are tied to the judiciary. As the judiciary when court is the world norm. As for the nature of the prosecution in western countries, it can be divided into two types: one is the prosecution and prosecutors' properties both consistent with the executive sequence, which does not have judicial attributes, such as in British and American; the other is the relative separation between prosecution and prosecutors attribute. Prosecutors have magistrate nature and belong to "stand-judge", but in the executive sequence, prosecutors are still vested to the Minister of Justice, represented by countries such as France, Germany, and Italy. Regardless of what type of prosecution as described above, it is not considered that prosecution belongs to the judiciary. Nevertheless, Chinese procuratorial organs are characterized as special legal supervisory authority, with the duty to uphold the dignity of law and guarantee uniform application of legal liability. So different from the prosecution authorities in the general sense, Chinese prosecution belongs to the judiciary.

Secondly, jurisdiction and prosecutorial power are being used independently according to the law. The Constitution, the law, the People's Courts exercise judicial power independently, while the 
People's Procuratorates exercise procuratorial power independently according to "by administrative organs, social groups or individuals" in the law. This suggests the so-called "independent". For one thing, it refers to the overall independence of the People's Court and People's Procuratorate rather than that of judges and prosecutors, who must go through the judicial committee or procuratorial committee for discussion and decision in some cases. For another thing, it only refers to the independence of the executive organs at all levels, social groups and individuals, but not the independence of the ruling party and elected officials. In contemporary countries ruled by law, "judicial independence" are the final implementation of the trial judge at the level of individual independence. Our judiciary is democratic centralism, pays attention to the collective role of the judiciary, and stresses leadership for approval checks, which is an overall independence [3].

Thirdly, the People's Courts, People's Procuratorate and public security organs for criminal cases should divide their responsibilities, cooperate together, and restrict mutually. This is one of the basic principles established in the Criminal Procedure Law enacted in 1979, 1982 and the provisions in the existing Article 135 of the Constitution. The reason for the constitutional provision is largely because of the painful lessons of history and its reflection. During a long period after the founding of China, under the influence of "Leftist" thoughts, the lack of logic and order among the three authorities along with few constraints of institutional relations has caused justice to become the tool of "class struggle as the key link" and the victim of political movements, leading to miscarriage of justice all over the field. Since then, this heavy lesson has been considered and summarized in constitutional amendment, and has become an important reason for the historical background and for the three constitutional authorities to write three articles.

Fourthly, the current judicial system puts emphasis on upholding the party's leadership. In China, the Communist Party is the ruling party and the core force of socialism with Chinese characteristics. The judiciary should comply with the party's leadership. The key question is how to deal with the relations between independent exercise of procuratorial power according to the law and judicial power of the party's leadership.

Fifthly, the judiciary is responsible for the authority. Our system of government is the People's Congress system. Article 2 of the Constitution states that "the official organ for people exercising state power is the National People's Congress and local people's congresses." Article 3 stipulates that the state administrative, judicial, procuratorial organs of the General Assembly by the people's congresses to which they are responsible and by which they are supervised. According to the provisions established by the People's Court Organization Law and the Organic Law of the People's Procuratorate, the judiciary at all levels produced by the authorities at all levels are controlled and supervised. This "separation of powers and checks and balances" is fundamentally different from the political system in western countries, which is "separation of three powers" referring to judicial power, legislative power, and executive power. But to be clear, our authorities do not implement "parliament and the executive" system, and the relationship between the executive authority and the judiciary is not that of leading or being led.

China's current judicial system is in line with China's national conditions, it is obvious that it has shortcomings. Particularly, during the implementation phase, a number of problems between external and internal relations of judiciary are highlighted and become an obstacle to achieve justice

External relations are mainly for local orientation. Our country is a unitary state, judicial power is vested in the central powers, People's Courts, People's Procuratorate, which are countries' courts and procuratorate. However, according to our current People's Court Organization Law and the Organic Law of the People's Procuratorate, People's Court, local people's procuratorates at all levels and local levels of the Attorney General by the General Assembly, local people's congress election, Vice President, the President, Vice-President, Judge, Deputy Attorney General, Attorney Committee, procurators by the Conference of Local People's Congress Standing Committee appointment. Funds and local people's courts at all levels of local people's procuratorates at various levels by the same level government budget, people's congresses at consideration allocated by the government. In the case of human, finance, and material are subject to the place, it is impossible to get rid of the 
intervention of local party at all levels and the government in the administration of justice, so the ultimate exercise of power cannot guarantee its independence.

Internal relations are mainly for administrative orientation. This is particularly acute in court. As the "judicial independence" is interpreted as a whole independent court, but not the implementation of independent judicial officers, so in personnel management and business that judges of People's Court handled internally, the chief tendency is very conspicuous. The former represents the equivalent to judges and civil servants in general, applying to the determination of judges' remuneration and business tiles by the administrative level; the latter showed the Court's internal business process aspects of the formation of various administrative style "approval" "consult" system, and the judicial committee and the full court on the relationship between the "Decision" and "implementation" of. Internal court administration not only suppresses the tendency of enthusiasm and professional pride of individual judges, but is also contrary to the law suit, which is a non-legalization of the internal structural relationships [4].

\section{The Necessity of Judicial Relative Rationality in Judicial Reform}

With China's reform and opening up, the development of the rule of law and the development process of the socialist market economic system, was once freeze as a single functional perspective of justice and integration in the world, which cannot meet the needs of modern China's development trend. With the awakening of the people and enhancing awareness of their rights, the expectations of citizen rights and social justice are increasingly strong. Thus, the importance of justice aroused common concern among people and scholars. The whole community focuses together on this kind of justice. Promoting China's judicial reform requires reflection of the reality. Under the new system, the interests of individuals in the society, and power as well as the demands for judicial protection gain political legitimacy. At the same time, since the planned economic system based on the traditional judicial structures is no longer able to complete the new mission of the times, it is forced to adjust itself, and thereby sparking thoughts on judicial reform. These two forces constitute the driving force of the judicial reform movement, which will push the original judicial system to the margins and cause entire social change. The reform will become the central issue that influences and restricts the areas of economic reform, political, cultural, etc. which cannot be ignored. It is in this context that relatively reasonable justice is called for in a variety of social life. From a macro perspective, there are mainly two reasons for the theoretical and practical necessity of judicial relative rationality in Chinese modernization.

The internal motivation. The economic base determines the superstructure. As a part of the superstructure, the study of the administration of justice is inseparable from economic development in order to explore the status quo. Additionally, the study on the urgency of judicial rationality is also inseparable from the interaction analysis of the reform and development of China's economic system.

"During those forty years from the founding of New China to the early 1990s, China's social and economic structure was a very uniform-public economic structure, the individual interests of the community required that such a structure should be discarded." In this economic structure, to be absorbed by the individual interests of the national interest, there was a deep personal attachment of citizens to the state, so an independent civil society force cannot be formed and the rights consciousness of citizens was very weak. Since the Third Plenary Session of the Working Party, the country has shifted its focus to economic construction. In particular, the establishment of market economy system changed the original structure and the rights structure of interests, which promoted the rapid economic development in China and increased people's living standards. Hence, businesses and individuals has become the subject of a market economy. When making their ideas into profound changes, companies and individuals resorted to "a court dispute" rather than "look for competent authorities to dispute", which implied the change of the concept.

Des Moines, a British jurist, says that "movement social progress, so far, is a movement from status to contract." It is because "the market cut off personal bondage, breaking the level of identity, whether abandoned dependent personality" so that our country is experiencing the progressive 
movement. The society dominated by "mechanical interlocking relationship" gradually transformed into a society dominated by the "organic relationship." In a market economy system characterized by contractual relationship, the free nature of market players has been fully demonstrated." Civil rights consciousness was thus awakened, precisely because the advantage of a huge market is that it allows the presence of a wide range of diversity. The existence of the diversity of market players must lead to the diversity of needs for rights, which has increased the burden of the judiciary. Therefore, marginalizing the original planned economy has gradually become the focus of attention, with a corresponding and more intense expectations that requires the judiciary to achieve the protection of their rights and remedies.

Productivity is the most revolutionary factor. In the process of continuous development of productive forces, the rights and obligations are determined by the productivity and constantly updated and developed accordingly. Faced with the requirements of the development of people's rights, due to the lag, rights law people have inherently legislative requirements cannot pass legislation in this institutional space was quickly reflected. In the face of forces determine the right relation to this objective laws of dialectical materialism, people of their rights to protection and relief concentrated judiciary. The content of rights law should be gradually updated according to changes in the development of the relations of production, and the laws of justice, to meet the needs of the people, so as to maintain the value of the law and to achieve the functioning of justice.

The external motivation. As for the dialectical relationship between the internal and external factors in China's judicial reform since the late 1980s, the judicial reform in the first few years was primarily driven by internal factors. However, in the 20th century, since the late 1990s, although China's judicial reform continued to be driven by internal factors, it was, at the same time, more and more influenced by the external pressures, showing trends of internal and external factors interacting simultaneously. The existence of external conditions indicates the need for judicial rationality.

By the end of November 2001, China's admission to WTO allowed China to integrate into the international economic community and follow the trend of world economic integration. Joining WTO has brought great influences on Chinese legal system, especially the judicial system and judicial reform. WTO is not only an important international organization in the international community, but also a great code from the substantial contents to procedural norms with distinctive characteristics. WTO set rules for countries to handle all aspects of the domestic economy, culture and social life, so how it will be integrated into national laws and affect the court handling the cases of legal basis has become the focus of public attention.

Since joining the WTO, China has enforced a number of judicial reform measures, with the purpose to make the provisions of the law reach WTO standards and requirements. The judicial system reform has shortened the gap between China and the WTO rules to a certain extent, but compared with rules of justice of WTO, our judicial system still fall far behind. In practice and operation process, based on the rules of WTO and our own, we can consider the factors of the two parties and make reasonable judicial decisions acceptable to both sides, which is conducive to the settlement of disputes, thus contributing to the sound development of both sides, which requires the guidance of judicial rationality theory. Economic globalization is an inevitable trend, as China becomes a member of the world community. A large number of cross-border disputes and foreign litigation require that our judicial system should follow internationally recognized legal norms for both greater resilience and arbitration judicial level. The legal requirements of "international standards" urges us to study the judicial rationality. An important goal of judicial reform is to meet the needs of citizens on the basis of respect for the judicial rules, which is the connotation of judicial rationality theory. China is a member in an increasingly globalized world, so the development of Chinese judicial reform is also inseparable from the impacts of the large environment. Therefore, judicial rationality will become an important guiding force of Chinese judicial reform and important goal of its practice. 


\section{The Obstacles to Judicial Relative Rationality in Judicial Reform}

The implementation of justice relative rationality requires a lot of conditions, among which it is believed that the most important ones are judicial independence, professional specialization of the judges, judicial procedures and accumulation of advanced judicial culture. Apart from these terms, in our judicial practice, there are still many factors obstructing the implementation of justice relative rationality [5].

After the founding of New China, the legal theory of state standards long dominated China's judicial practice, which means that the law was a manifestation of the will of the ruling class and regarded as a tool of the ruling class. In this instrumentalist view of law, "justice as an integral part of this kind of ruling tool means nothing." Justice has been positioned as the country's "Dao" with its primary or sole mission to achieve political hostile elements of dictatorship. Judicial independence as a "patent" of bourgeois was criticized in theory, but was abandoned in practice. Judicial power was not separated from the national power of the ruling class, but as a vassal of the executive power, was exercised merely to punish counterrevolutionaries and criminals who damaged social order, in order to maintain social order and rules. Subsequently, the independence of courts and judges could not be guaranteed, the judicial process was arbitrarily trampled and judicial culture was in a backward state. In short, this single concept of judicial function has increasingly become an obstacle to the development of law and its flaws become increasingly apparent as time went by, which are roughly as follows.

Firstly, the justice did not get truly independent status. First of all, there is no independence of the judicial power. Due to a long period of our ideological struggle, independence of the judiciary has also been regarded as the monopoly of the capitalist countries for a long time. Although with the development of market economy and the acceleration of the process of the rule of law, the awareness of judicial independence has been significantly raised and promoted, the principle of judicial independence in institutional settings has not been truly implemented.

In addition, the Court did not get a real independence, although Article 126 of China's constitution in 1982 stated that "people's courts exercise judicial power independently according to law, by administrative organs, social groups, or individuals." From the stipulation, thus, we can see the principle of judicial independence is our principle of independence of judgment in the form of getting established. But in the actual operation of the judiciary, there are a series of situations that hinder the courts from operating independently. These include the fact that the financial sources come from the Administrative Court, as well as that the personnel system, the personnel arrangements and other administrative activities must obey to the court.

Finally, the judge did not get independent status, because the principle of judicial independence has been established to organize the independence of the judiciary rather than that of judges. "Independence of judges, the core and the cornerstone of its system, is deprived, so that our principle of judicial independence and internationally accepted judicial principle of independence are two essentially different connotations in the system from the shape and spirit." In practice, judges in the judicial process are not able to really, fully and completely express their will and judgment. Under the control of administrative justice and the layers of management, the judges are bound to become the spokespeople of superior officers, institutions, and organizations. As a result, they cannot really judge the cases independently, which is a serious impediment to the realization of justice relative rationality.

Secondly, judges tended to have more administrative functions. Recalling the professional development of judges, there are only strong administrative functions. In the selection process of judges, taking the popular road $_{2}$ judges have the same treatment as civil servants in salaries; judges and general staff do not have much differences in job security and discipline. These greatly influenced the formation of judge professionalization. The professional development of administrative judges on the relative rationality to achieve justice caused great obstacles, so that judges can only be a career of professional development in the air, but cannot form the judge occupational groups. In the face of changing society, the judges with a strong administrative role are 
not able to respond to the need for justice that the society presented, not to mention the judicial relative rationality which has the function of dynamic communication and stability.

Thirdly, judicial process and procedures were ignored. Because of the legislation in the light of the program and the impact of procedural law in national selfishness of ideas, some of the judiciary and judicial officers even think of procedural law only constraint parties and other participants in the proceedings, the judiciary cannot be bound by legal procedures and institutions. In fact, in our country, it is wrong that judicial misjudges often happen to not applicable substantive law, but appear on the law with not strict execution of the process and imperfect procedural law itself.

Fourthly, the backwardness of judicial culture. Due to historical and practical reasons, China's current judicial culture includes some components that are not suited to a modern judicial culture. First, for judicial authorities in the face of power, the influence of power is greater than that of the legal concept. The failure of judicial authority to make judicial judgment cannot persuade the public, which makes the realization of justice relative rationality lack a popular base, affecting its implementation. Secondly, the current standard judicial culture results from the obligations under the influence of standard values, as well as the purpose of our action in favor of punishing criminal behaviors and safeguarding the overall interests of the community, especially the protection of the rights of individuals accused of poor.

\section{The Efforts to Achieve Judicial Relative Rationality in Judicial Reform}

Firstly, construct a truly independent judiciary. After several generations of efforts, China has finally established the "rule of law", and finally embarked on the road of the rule of law and constitutionalism. Constitutionalism aims to restrict the government power and protect human rights by law, so as to ensure judicial justice. To achieve justice, true judicial independence is a critical and fundamental prerequisite. Independence of the judiciary should include three meanings. The first one is the separation of judicial power from the national power system, which brings the independent exercise. The second is that the Court can exercise judicial power independently free from interference by other factors, while the last one is that the judges are only in charge of the Constitution and laws, without interference of other factors. Judicial independence can be regarded as a prerequisite of judicial relative rationality.

Secondly, the implementation of judges' professional specialization. The process of human law reveals a liberty: justice relative rationality necessarily call for career specialization of judges, so that in the face of legal uncertainty, the judges must resort to legal principles. Legal principles "is the tendency of officials reason a behavior pattern, it does not have the power of having a regular importance, prone to conflict does not exist strong grounds overwhelm the other side." When cases involve two or more principles with mutual conflicts, the judges must carefully weigh the relative strength of both parties, in order to make a reasonable judgment. This necessarily requires judges to master deep knowledge and good professional spirit, which contributes to the judge professional specialization. So the trend of professional specialization has become increasingly significant for judges.

Thirdly, improve the judicial process system. In our modern society, to achieve publicity and civil procedural right and to pursue constitutional system and its value are inseparable. Constitutional system must be provided and procedural rights of citizens must be expanded. In order to make the rule of law and justice to be realized, the judiciary must also adhere to a series of procedural principles. Any departure from this principle may all lead to judicial injustice.

Fourthly, cultivate advanced judicial culture. Judicial culture is a premise of judicial relative rationality that must be solved. Advanced judicial culture is not only the results of consolidating judicial reform, but also conducive to the smooth progress of China's judicial reform on a higher starting point. Support from citizens is the driving force behind our judicial reform. It is necessary to continue developing advanced legal culture and increase citizen's participation in the justice initiative, in order to provide an inexhaustible impetus for our relatively reasonable justice. 


\section{Conclusion}

In the background of rapid development of the society, the rapid transformation of the People's Court in a timely manner in response to the needs of social development is required. Judicial reform should be actively implemented, which opens up a new modern judicial process in contemporary China. In the process of judicial reform, it is important to ensure relatively reasonable justice in favor of civil rights and the protection of relief, help stabilize social conflicts, maintain social order, and at the same time, steadily push forward the continuous development of the society. Therefore, great efforts should be made to achieve judicial relative rationality in judicial reform.

\section{References}

[1] X.Zhang, Contemporary China's judicial independence, J. People's Court News, 5(2007) 46-47.

[2] C.Li, WTO and International Law, J. Applicable Law 11(2006) 26-30.

[3] C.Y.Wang, Research on the relative rationality of the law, J. Journal of Nanjing University 12(2009) 56-58.

[4] J.X.Li, Problems and Improving Measures in current judicial system, J. Law Review .9(2009) $19-22$.

[5] Y.X.Zhang, Cultural reflections on judicial reform, J. Legal science. 4(2007) 129-132. 